\title{
Erratum to: Outpatient, non-antibiotic management in acute uncomplicated diverticulitis: a prospective study
}

\author{
D. Isacson ${ }^{1,3}$ - A. Thorisson ${ }^{2,3} \cdot$ K. Andreasson ${ }^{1}$ - M. Nikberg ${ }^{1,3} \cdot$ K. Smedh $^{1,3}$ • \\ A. Chabok ${ }^{1,3}$
}

Published online: 19 June 2015

(C) Springer-Verlag Berlin Heidelberg 2015

Erratum to: Int J Colorectal Dis

DOI 10.1007/s00384-015-2258-y

The original version of this article unfortunately contains an error in page 4 , third line of the first paragraph under "Discussion" section. which reads, "The previous studies does not only strengthen that the non-antibiotic policy....". It should read, "This study does not only strengthen previous studies that the non-antibiotic policy...".

The correct sentence is presented as below:

"This study does not only strengthen previous studies that the non-antibiotic policy in acute uncomplicated diverticulitis is safe and applicable in clinical practice, but it also adds evidence that it is safe to discharge patients directly from the emergency department."

The online version of the original article can be found at http://dx.doi.org/ 10.1007/s00384-015-2258-y.

D. Isacson

ddisacson@gmail.com

1 Colorectal Unit, Department of Surgery, Västmanland's Hospital Västerås, SE-72189 Västerås, Sweden

2 Department of Radiology, Västmanland's Hospital Västerås, Västerås, Sweden

3 Centre for Clinical Research of Uppsala University, Västmanland's Hospital Västerås, Västerås, Sweden 